\title{
Rent Car Online Boro
}

\author{
Adi Viranata, Departemen Informatika, Institut Sains dan Teknologi Terpadu Surabaya, Eka Rahayu \\ Setyaningsih, Departemen Informatika, Institut Sains dan Teknologi Terpadu Surabaya, Tjwanda \\ Putera Gunawan, Departemen Informatika, Institut Sains dan Teknologi Terpadu Surabaya
}

\begin{abstract}
Abstrak-Website sudah berkembang di masyarakat sekarang dengan pesatnya. Banyak sekali penggunaannya yang dibutuhkan di dalam kegiatan sehari-hari. Dibandingkan jaman dahulu, sekarang telah banyak orang yang melakukan aktifitas sehari-hari melakukan secara online. Mulai dari kebutuhan kecil hingga kebutuhan yang besar. Semua dilakukan secara online tanpa harus keluar rumah. Website rent car online Boro pada Penelitian ini adalah salah satu solusi untuk keperluan sehari-hari dalam menyewa sebuauh mobil. Dilengkapi dengan fitur status order pada halaman pelanggan yang membuat pelanggan dapat memantau ordernya kapanpun dan dimanapun. Semua sistem pengerjaan mulai dari operator, sopir, dan admin dibuat secara efisien sehingga proses sewa mobil menjadi mudah dan menyenangkan. Sistem ini diharapkan dapat membantu mempermudah pelanggan untuk melakukan penyewaan dengan memilih waktu yang sesuai, jenis mobil sesuai kebutuhan, harga sewa dan supir yang dikehendaki. Pembayaran sewa mobil juga dapat dilakukan dengan mudah melalui transfer antar bank. Semua sistem dari pemesanan, pembayaran, proses pengiriman mobil, perjalanan selama sewa mobil hingga pengembaliannya dilakukan secara online.
\end{abstract}

Kata Kunci-Boro, Car, Online, Rent, Website.

\section{Pendahuluan}

$P^{2}$ erkembangan website yang sangat pesat di masyarakat mempermudah semuanya baik dari segi efisiensi waktu transaksi, memilih sesuatu yang sesuai kebutuhan dan juga pembayaran untuk transaksi tersebut. Dibandingkan jaman dahulu, sekarang hampir semua bidang usaha menggunakan website online sebagai sarana untuk mempromosikan usahanya mulai dari bisnis kelas kecil, kelas menengah, sampai usaha kelas besar sekalipun. Usaha rent car sekarang ini juga mengalami perkembangan yang cukup pesat dari beberapa tahun belakangan ini, pertumbuhan pelaku bisnis rent car itu terutama terlihat di sudut-sudut kota besar seperti Jakarta, Bandung, Semarang, Yogyakarta, Medan, Makassar, Palembang, Batam, Pekanbaru, Malang dan Surabaya. Namun tidak bisa dipungkiri fakta bahwa sebenarnya di kota yang kecil pun usaha rent car mengalami perkembangan yang bagus juga. Bisnis rent car adalah

\section{Oktober 2020}

Adi Viranata, Departemen Informatika, Institut Sains dan Teknologi Terpadu Surabaya, Surabaya, Jawa Timur, Indonesia (e-mail: adiviranata@gmail.com)

Eka Rahayu Setyaningsih, Departemen Informatika, Institut Sains dan Teknologi Terpadu Surabaya, Surabaya, Jawa Timur, Indonesia

Tjwanda Putera Gunawan, Departemen Informatika, Institut Sains dan Teknologi Terpadu Surabaya, Surabaya, Jawa Timur, Indonesia sebuah contoh peluang usaha di rumah yang dapat dilakukan oleh siapa saja sehingga sangat diminati oleh masyarakat. Bisnis rent car jaman dulu memiliki kelemahan dimana pelanggan yang datang kerumah pemilik mobil, memilih mobil dan membayar sewa dengan uang tunai disana, alangkah praktisnya jika semua hal tersebut dari memilih mobil, pengiriman mobil, pendataan penyewa dan pembayaran sampai selesai dilakukan secara online tanpa harus pelanggan melangkah ke luar rumah.

\section{TEORI DASAR}

Setelah membaca penjelasan pada Bab I mengenai latar belakang, tujuan, ruang lingkup, metodologi, dan sistematika pembahasan, pada bab ini akan membahas mengenai teori-teori yang digunakan dalam pembuatan website. Teori-teori yang akan dibahas mencakup Semantic Elements, Bootstrap Components, CSS, Google Maps API, dan Midtrans serta teori-teori penunjang untuk membantu pengerjaan Penelitian ini.

\section{A. Semantic Elements}

Unsur semantik yang akan digunakan pada pengerjaan Penelitian merupakan penandaan kata yang mempunyai struktur elemen baru yang akan memudahkan pembuatan Penelitian ini untuk membedakan isi dari sebuah dokumen web yang akan digunakan oleh customer website tersebut Unsur semantik ini menggunakan metode markup baru HTML5 yang terbaru jadi selama browser kita update, semantic element akan berjalan dengan baik di browser tersebut. Sehingga tidak akan berpengaruh secara langsung kepada pengguna baik dari segi kegunaan maupun efektifitas dari pemakaian dari sebuah website, namun markup baru ini memiliki fitur khusus yaitu dapat menyederhanakan penulisan halaman pada struktur isi HTML dan membuat sebuah website menjadi lebih modern dan menarik. Selain itu, website akan menjadi lebih efisien dan mudah untuk dimengerti oleh user dari website tersebut. Jadi selama semantic element digunakan dengan baik dan benar ini akan memberikan kegunaan bagi suatu website.

\section{B. Bootstrap Components}

DataTransfer biasanya Bootstrap adalah front-end framework yang simple, bagus dan luar biasa yang mengedepankan tampilan untuk mobile device (Handphone, smartphone, dan tablet.) guna mempercepat dan mempermudah pengembangan website. Bootstrap menyediakan HTML, CSS dan Javascript siap pakai dan mudah untuk dikembangkan. 


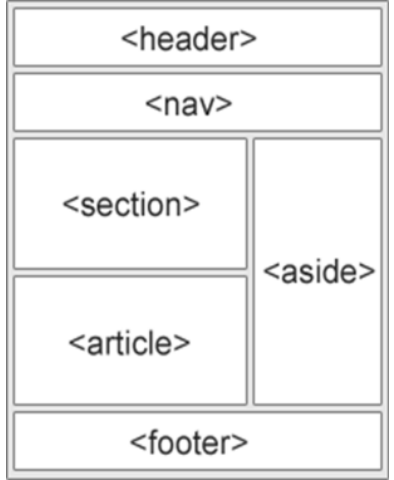

Gambar. 1. Penerapan Elemen Semantic

Bootstrap juga merupakan alat untuk mendesain UI web. Bootstrap biasanya dikenal sebagai sebuah library CSS yang dapat digunakan untuk membuat responsive layout. Bootstrap merupakan framework untuk membangun desain web secara responsif. Artinya, tampilan web yang dibuat oleh bootstrap akan menyesuaikan ukuran layar dari browser yang digunakan baik di desktop, tablet ataupun mobile device. Fitur ini bisa diaktifkan ataupun dinon-aktifkan sesuai dengan keinginan. Sehingga, ketika membuat web untuk tampilan desktop dan apabila dibuka oleh mobile browser maka tampilan dari web yang dibuat dapat beradaptasi sesuai layar. Dengan bootstrap dapat membangun web dinamis ataupun statis dengan mudah sesuai dengan kebutuhan.

1) Dropdowns

2) Input Groups

3) Labels

4) Jumbotron

5) Page Header

6) Progress Bars

7) List Group

8) Panels

9) Wells

\section{ANALISA SISTEM}

Pada bab ini akan dijelaskan mengenai analisa sistem dan alur kerja sistem, untuk sistem yang digunakan pada pembuatan Penelitian ini. Dalam analisa sistem ini terdapat beberapa hal penting yang akan dicantumkan, mulai dari analisa sistem yang serupa dengan mengedepankan beberapa tujuan tertentu sampai sistem yang telah dibuat pada pengembangan Penelitian dan spesifikasi kebutuhan untuk mencapai sistem yang lebih baik dan lebih sesuai untuk mengahadapi kebutuhan-kebutuhan dan masalahmasalah yang akan dihadapi pada saat sistem digunakan.

\section{A. Analisis Website Sejenis}

Pada pembuatan website Penelitian ini bertujuan sebagai wadah untuk membuat sebuah website yang belum pernah ada yaitu sebuah website rent car online dimana mulai dari proses pengorderan, pengambilan mobil sampai pengembalian semuanya dilakukan secara online. Websitewebsite sejenis seperti tiket.com, okkarent.co.id dan system pemesanan pada gojek menjadi acuan dalam membuat Penelitian.
Fitur-fitur yang digunakan oleh tiket.com akan digunakan oleh website yang akan dibuat adalah dengan terdapatnya order online, realtime process, pengiriman mobil dan pengembalian yang tersedia. Realtime process mempunyai peran yang sangat besar dalam Penelitian ini karena pelanggan dapat melihat langsung proses penyewaan yang dilakukan dimanapun. Tidak hanya itu pada penelitian ini dilengkapi dengan Google Maps untuk sopir agar sopir dapat menemukan tempat tinggal pelanggan dengan mudah berdasarkan rute yang di tentukan.

TABEL I

TABEL PEMBANDING DENGAN WEBSITE SEJENIS

\begin{tabular}{lcc}
\hline \multicolumn{1}{c}{ Fitur } & Tiket.com & Penelitian \\
\hline Tampilan Menarik & $\mathrm{v}$ & $\mathrm{v}$ \\
Proses Realtime & $\mathrm{v}$ & $\mathrm{v}$ \\
Estimasi Waktu Sopir & $\mathrm{v}$ & $\mathrm{v}$ \\
Notifikasi Web dan Email & $\mathrm{v}$ & $\mathrm{v}$ \\
Lokasi Map & $\mathrm{x}$ & $\mathrm{v}$ \\
\hline \hline
\end{tabular}

\section{B. Spesifikasi Kebutuhan}

Pada sub bab ini akan dibahas tentang spesifikasi kebutuhan yang akan digunakan dalam pembuatan Penelitian. Pada pembuatan Penelitian ini berbasis website sehingga mememerlukan komponen-komponen yang digunakan untuk menunjang sistem website agar dapat memenuhi kebutuhan. Pada umumnya spesifikasi kebutuhan memiliki tujuan mencatat berbagai kebutuhan fungsional. Kebutuhan fungsional diambil dari kebutuhan pelanggan terhadap fungsi-fungsi yang ada didalam sistem, aturanaturan bisnis beserta atribut kualitas yang mengiringinya. Pada masing-masing kebutuhan fungsional, dilakukan analisis terhadap input, proses, dan output. Developer dalam melakukan pengembangan sistem dan pembaharuan sistem harus mencatat spesifikasi kebutuhan yang diperlukan oleh sistem untuk dikembangkan atau diperbaharui.

\section{Deskripsi Sistem}

Sistem pada website rent car online ini berada pada halaman operator, dimana operator yang mengatur seluruh alur dan jalannya sebuah sistem pennyewaan online pada Penelitian ini. Operator memiliki beberapa tugas yang wajib dilakukan seperti member perintah order, mereview setiap pengataran dan pengiriman kurir, melakukan mengesahan konfirmasi pembayaran dengan menggunakan metode midtrans yang sudah terkenal dan terpercaya di masa sekarang ini yaitu menggunakan metode pembayaran dengan pihak ketiga.

Selain melakukan hal tersebut, operator juga bertugas untuk melakukan perintah kepada kurir yang dipilih untuk melakukan pengantaran mobil dan juga pengambilan mobil ke pelanggan. Setelah kurir melakukan pekerjaannya yaitu mengantarkan atau mengirimkan mobil kepada pelanggan, operator bertugas untuk melakukan review pada pekerjaan yang telah dilakukan oleh kurir untuk menandakan bahwa pekerjaan yang telah dilakukan oleh kurir sudah benar dan selesai. Operator juga dapat mengulang mengecek order dari pelanggan web. Setelah operator mengecek pembayaran dari pelanggan lewat sistem pembayaran midtrans yang 
digunakan oleh website rentcar online boro. Operator akan meneruskan order dari pelanggan ke sopir yang akan mengantarkan mobil ke pelanggan. Jika menggunakan sopir, maka akan menggunakan sopir sesuai pesanan pelanggan. Jika tidak menggunakan sopir, maka mobil akan diantar oleh sopir pilihan sistem yang akan dilakukan oleh operator. Sopir akan diberi notifikasi 1 jam sebelum order dijalankan.

\section{DESAIN SISTEM}

Berikut dijelaskan mengenai data rich diagram yang akan dibuat pada sistem pemesanan website ini. Dibawah ini merupakan gambaran struktur pemesanan yang akan dipakai dalam pembuatan website rent car online.

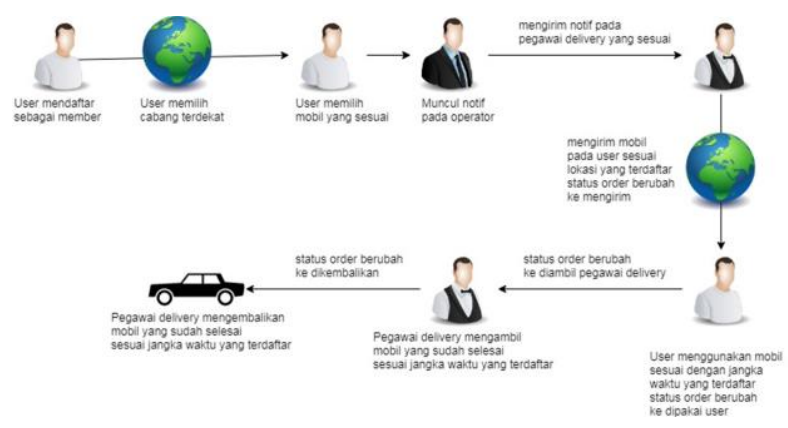

Gambar. 2. Bagan Sistem Rent Car Online

Sistem penyimpanan desain mempunyai 5 modul besar. Masing-masing modul mempunyai peranan masing-masing. Modul login merupakan modul yang harus user gunakan apabila ingin masuk dan menggunakan fasilitas dalam website ini. Modul home adalah modul yang akan dijalankan ketika user berhasil login dan menampilkan berbagai macam halaman web yang telah disimpan oleh user. Modul template merupakan modul yang ditampilkan ketika user memilih halaman template atau mengklik tombol create new. Modul admin hanya dapat diakses oleh admin.

\section{IMPLEMENTASI}

Pada bab ini akan dilakukan implementasi dan integrasi terhadap sistem website. Tahapan ini dilakukan setelah dilakukan analisa dan spesifikasi pada aplikasi yang akan dibuat dan desain sistem juga telah dibuat. Setelah dilakukan analisa, spesifikasi, implementasi, dan integrasi pada web, maka akan menghasilkan detail dari web. Jadi bab ini akan menjelaskan mengenai segmen-segmen hasil implementasi dari desain yang telah dibuat pada bab sebelumnya.

\section{A. Incremental Implementasi Pertama}

Pada subbab ini akan dijelaskan tentang implementasi tahap incremental satu kedalam bentuk program dari segmen program yang sudah dibahas pada bab sebelumnya yaitu mengenai beberapa segmen. Dalam penanganan user terdapat beberapa segmen yang disediakan untuk user, seperti segmen login dan segmen register. Login merupakan salah satu segmen terpenting pada website rent car online. Register merupakan salah satu segmen yang saling bersangkutan dengan segmen login pada website rent car online. Setelah login sukses, pelanggan dapat melakukan order sewa mobil.

\section{B. Incremental Implementasi Kedua}

Implementasi tahap incremental kedua akan dijelaskan dalam bentuk program tentang halaman utama pelanggan. Halaman ini adalah halaman yang digunakan oleh pelanggan untuk melakukan sebuah order pada sistem. Jika pelanggan belum melakukan login, maka pelanggan akan dilemparkan ke halaman login untuk melakukan login terlebih dulu sebelum melakukan order. Jika pelanggan belum register, maka harus register dulu.

\section{UJI COBA}

Uji coba yang telah dilakukan pada aplikasi yang dibuat pada penelitian ini adalah pembahasan terhadap kuisoner yang dibagikan kepada para pengguna selama beberapa periode penggunaan web, hasil analisa pengunggahan data real yang dilakukan pada sistem web ini.

\section{A. Uji Coba Kelayakan Aplikasi}

Akan dilakukan uji coba kelayakan aplikasi pada sistem yang telah dibuat. Sistem akan diuji coba dengan membuat sebuah desain webpage. Uji coba kelayakan aplikasi akan dilakukan dengan menguji berbagai fitur apakah telah berjalan dengan benar.

TABEL II

DAFTAR FITUR YANG DIUJI COBA FUNGSIONALITAS

\begin{tabular}{lllll}
\hline \hline \multirow{2}{*}{ No } & \multirow{2}{*}{ Nama Fitur } & Kriterian kinerja fitur & Baik & $\begin{array}{c}\text { Tidak } \\
\text { Baik }\end{array}$ \\
\hline 1 & Tampilan Awal & Efektifitas fungsional & $\sqrt{ }$ & \\
& & Resposinevess & $\sqrt{ }$ & \\
\hline 2 & Tampilan Login & Login berfungsi & $\sqrt{ }$ \\
& Pelanggan & Efektifitas fungsional & $\sqrt{ }$ \\
& & Resposinevess & $\sqrt{ }$ \\
\hline 3 & Tampilan & Register berfungsi & $\sqrt{ }$ \\
& Register & Efektifitas fungsional & $\sqrt{ }$ \\
\hline 4 & Pelanggan & Resposinevess & $\sqrt{ }$ \\
& Pelanggan & Sistem order berfungsi & $\sqrt{ }$ \\
& Edit profile pelanggan & $\sqrt{ }$ \\
\hline 5 & Beranda Pegawai & Lihat histori pelanggan & $\sqrt{ }$ \\
& & Dashboard status kerja & $\sqrt{ }$ \\
& Sistem jalankan order & $\sqrt{ }$ \\
& Konfirmasi & $\sqrt{ }$ \\
& & pembayaran & \\
& Status website & $\sqrt{ }$ \\
& Atur tampilan website & $\sqrt{ }$ \\
& & Pengaturan harga & $\sqrt{ }$ \\
\hline \hline
\end{tabular}

\section{B. Angket}

Selain menguji coba sistem web internal yang telah dibuat, pengujian juga akan dilakukan pada user website. Pengujian yang akan dilakukan menggunakan kuisioner yang disebar kepada 20 orang, yaitu pengguna, pegawai rental dan orang yang mengerti IT. Diberikan pada pengguna untuk mengetahui sejauh mana kemudahan dalam menyewa mobil, diberikan pada pegawai rental untuk mengetahui kemudahan dan kejelasan dalam mengoperasikan website tersebut dan menerima pesanan serta complain dari pengguna dan diberikan bagi yang mengerti IT untuk mengetahui kemudahan yang bias diterima bagi pengguna dan pegawai. Hasil survei yang diperoleh untuk perkembangan website selanjutnya.

Metode kuesioner bertujuan untuk mengetahui respon dari user mengenai sistem yang telah dikembangkan. 
Metode kuesioner dipilih karena dapat menghasilkan datadata yang mudah diolah dan dimengerti. Metode kuesioner dinilai lebih efisien dan praktis untuk dilakukan.

TABEL III

DATA HASIL KUESIONER BAGIAN 1

\begin{tabular}{|c|c|c|c|c|c|c|}
\hline No & Pertanyaan & 1 & 2 & 3 & 4 & 5 \\
\hline 1 & $\begin{array}{l}\text { Apakah perlu rent car } \\
\text { dilakukan secara online? }\end{array}$ & $0 \%$ & $10 \%$ & $30 \%$ & $50 \%$ & $10 \%$ \\
\hline 2 & $\begin{array}{l}\text { Apakah anda ingin } \\
\text { mencoba mobil secara } \\
\text { online? }\end{array}$ & $5 \%$ & $0 \%$ & $25 \%$ & $45 \%$ & $25 \%$ \\
\hline 3 & $\begin{array}{l}\text { Apakah rent car online } \\
\text { dapat dipercaya? }\end{array}$ & $5 \%$ & $10 \%$ & $0 \%$ & $35 \%$ & $50 \%$ \\
\hline 4 & $\begin{array}{l}\text { Apakah fitur status } \\
\text { order penting bagi } \\
\text { pelanggan? }\end{array}$ & $5 \%$ & $10 \%$ & $5 \%$ & $20 \%$ & $60 \%$ \\
\hline 5 & $\begin{array}{l}\text { Apakah fitur Google } \\
\text { Maps penting bagi } \\
\text { sopir? }\end{array}$ & $0 \%$ & $10 \%$ & $20 \%$ & $30 \%$ & $40 \%$ \\
\hline 6 & $\begin{array}{l}\text { Apakah user friendly } \\
\text { penting untuk sebuah } \\
\text { website rent car online? }\end{array}$ & $0 \%$ & $5 \%$ & $20 \%$ & $45 \%$ & $30 \%$ \\
\hline 7 & $\begin{array}{l}\text { Apakah midtrans } \\
\text { terpercaya? }\end{array}$ & $5 \%$ & $5 \%$ & $40 \%$ & $35 \%$ & $15 \%$ \\
\hline
\end{tabular}

Kuesioner untuk pengguna ini menunjukkan bahwa penggunan ingin mencoba mobil dahulu sebelum menyewanya sebanyak $45 \%$ dan fitur status order diminati banyak pengguna sebanyak $60 \%$.

TABEL IV

DATA HASIL KUESIONER BAGIAN 2

\begin{tabular}{llccccc}
\hline \hline No & \multicolumn{1}{c}{ Pertanyaan } & 1 & 2 & 3 & 4 & 5 \\
\hline 1 & $\begin{array}{l}\text { Apakah halaman } \\
\text { pelanggan sudah user } \\
\text { friendly? }\end{array}$ & $0 \%$ & $5 \%$ & $25 \%$ & $45 \%$ & $25 \%$ \\
2 & $\begin{array}{l}\text { Apakah sistem order } \\
\text { halaman pelanggan } \\
\text { berjalan dengan baik? } \\
\text { Apakah sistem invoice } \\
\text { pada pelanggan berjalan } \\
\text { dengan baik? }\end{array}$ & $5 \%$ & $5 \%$ & $25 \%$ & $15 \%$ & $60 \%$ \\
$\begin{array}{l}\text { Tampilan pada halaman } \\
\text { pelanggan apakah sudah } \\
\text { cukup user friendly? }\end{array}$ & $5 \%$ & $10 \%$ & $5 \%$ & $55 \%$ & $30 \%$ \\
\hline \hline
\end{tabular}

Kuesioner untuk orang IT ini menunjukkan bahwa sistem order halaman pelanggan berjalan dengan baik sebanyak $60 \%$ dan Tampilan pada halaman pelanggan apakah sudah cukup user friendly sebanyak $70 \%$.

TABEL V

DATA HASIL KUESIONER BAGIAN 3

\begin{tabular}{llccccc}
\hline \hline No & \multicolumn{1}{c}{ Pertanyaan } & 1 & 2 & 3 & 4 & 5 \\
\hline 1 & $\begin{array}{l}\text { Apakah tampilan } \\
\text { halaman pegawai } \\
\text { mudah dimengerti? } \\
\text { Apakah status order } \\
\text { berjalan dengan baik? }\end{array}$ & $10 \%$ & $5 \%$ & $55 \%$ & $20 \%$ & $10 \%$ \\
Apakah sistem order \\
berjalan dengan baik? \\
Apakah Google Maps \\
berjalan dengan baik?
\end{tabular}

Kuesioner untuk pegawai rental ini menunjukkan bahwa status order berjalan dengan baik sebanyak $70 \%$ dan Google Maps berjalan dengan baik $80 \%$.

\section{PENUTUP}

\section{A. Kesimpulan}

Pada subbab ini akan dibahas mengenai kesimpulan dari pembuatan web Penelitian ini yang didapat setelah selesai membuat Penelitian ini. Kesimpulan didapatkan berdasarkan pengalaman yang diperoleh selama masa pembuatan Penelitian rent car online boro ini. Kesimpulan-kesimpulan yang dapat ditarik dari pembuatan Penelitian ini adalah.

1) Berdasarkan uji kelayakan aplikasi, user menyatakan kendala yang terjadi dalam melakukan order penyewaan yaitu tidak dapatnya melakukan multi order atau order lebih dari satu sebelum proses menyewa yang sebelumnya belum selesai.

2) Berdasarkan angket uji coba, responden dari angket menyatakan beberapa responden mengalami kebingungan dalam proses order status dalam halaman operator, akan tetapi tidak sedikit juga yang merasa senang dengan dengan sistem atur order dalam halaman operator.

3) Berdasarkan angket uji coba, responden yang merasa senang dengan desain tampilan interface website rent car online yang bagus. Tampilan yang user friendly membuat pelanggan, kurir, maupun operator dapat dengan mudah mengoperasikan sistem website rentcar online.

\section{B. Saran}

Selain menarik kesimpulan dari pembuatan Penelitian ini, berdasarkan proses pembuatan Penelitian ini terdapat beberapa saran yang mungkin berguna bagi pembaca dalam mengembangkan topik ini lebih lanjut. Beberapa saran yang ada antara lain adalah:

1) Pertimbangkan kemudahan untuk user menggunakan sistem website rent car online suapaya user tidak mengalami kesulitan dalam mengoperasikan website.

2) Pertimbangkan pemesanan multi order agar pelanggan dapat melakukan order lebih dari satu.

3) Berikan panduan untuk penggunaan sistem rent car online untuk kurir dan operator untuk pertama kali penggunaan.

\section{DAFTAR PUSTAKA}

[1] Astamal, Rio, 2006. Mastering Kode HTML edisi ke -2. Surabaya.

[2] Brown, Gillian and George Yule, 1983. Discourse Analys. New York:Cambridge University Press.

[3] Forshaw, Joseph M.; Cooper, William T., 2006. Parrots of The World. TFH Publications.

[4] Google Maps API, https://developers.google.com/maps/?hl=id diakses pada 12 April 2018.

[5] Krisch, Peter, 2013. Cascading Style Sheet (CSS) Tutorial Using Notepad, http://www.allcreativedesigns.com.au/css_tutorial_notepad_ 2013.pdf diakses pada 12 April 2018.

[6] Meloni, Julie C., 2012. Sams Teach Yourself HTML, CSS, and JavaScript All in One. Sams Publishing. 